\title{
Prognostic factors for the elderly with proximal femoral fracture
}

\author{
T. B. YOUNG* AND A. C. C. GIBBS $\dagger$
}

* Accident and Orthopaedic Department, Victoria Infirmary, Glasgow and $\dagger$ Department of Community Medicine, University of Manchester

\section{SUMMARY}

A prospective study of 125 elderly patients (over 65 years) with proximal femoral fracture was carried out to compare pre-fracture sociomedical factors with the local and general complications following surgical treatment, in predicting mortality and length of stay. A poor pre-fracture mental state was more important than associated physical illness in predicting mortality. Pre-fracture mobility state was the most useful early prognostic predictor of length of hospitalization. Post-operative general complications were the most significant in predicting mortality and length of hospitalization, and more important than failure of operative technique.

\section{INTRODUCTION}

It has been shown that mortality following hip fracture decreases gradually after the fracture and eventually becomes parallel with the mortality of the general population of similar age. This duration may vary from 2 months (Dahl, 1980) to 18 months (Jensen \& Tondevold, 1979). Pre-injury factors which influence this mortality and hospitalization time have been identified as age, source of admission, social status, associated illness, mental state, and mobility (Baker et al., 1978; Miller, 1978; Ceder et al., 1981; Jensen, 1984). However, the relative significance of each has not been established. The outcome of any operation is influenced by post-operative complications but it is not known if these are more important than factors already present before injury.

The aim of this study was to establish the relative importance of the pre-fracture factors to each other and their importance relative to post-operative complications.

\footnotetext{
* Present address and address for correspondence: Mr T. B. Young, Accident and Emergency Department, Lincoln County Hospital, Servell Road, Lincoln
} 


\section{METHODS}

A total of 210 consecutive patients above 65 years with proximal femoral fractures $\stackrel{\frac{3}{\circ}}{\circ}$ admitted during 1981 to the Victoria Infirmary, Glasgow were assessed for the purpose $\overrightarrow{\vec{F}}$ of this study at the time of injury and followed up by the authors. Due to technical difficulties only 129 cases were finally included and these were considered suitable for the study as they were randomly distributed throughout the original list. A further four patients who were not operated on were excluded from the statistical analysis.

The following factors were identified at the time of presentation to the Accident and $\%$ Emergency Department in patients over 65 years who had incurred a fracture of the hip. $\vec{\circ}$

\section{Mental State}

This was defined as:

fully alert-oriented in time and place on presentation and able to give a full account of $\frac{\mathrm{N}}{\mathrm{G}}$ the incident;

confused-oriented at presentation but did not know the details of the accident; demented-disoriented at presentation and classed as such by independent specialist assessment.

\section{Associated Illnesses}

These were diagnosed from examination at presentation and previous medical records్ Only illnesses requiring treatment or chronic disabling conditions were included.

\section{Mobility (prior to fracture)}

This was defined as:

fully mobile;

partial mobility-needing aid to walk;

immobile-totally bed- or chair-bound.

\section{Age}

Only patients aged 65 years and above were included.

\section{Source of Admission}

This was classified as follows:

Group I -patients who came from their own homes;

Group II-patients who came from institutions, e.g. elderly persons' homes, nursing homes, etc. 


\section{Medication}

Patients on one or more regular medications for at least 3 months before the fracture were included in this group.

Following admission to the ward each patient was followed up and any post-operative complications noted.

The time of death or discharge was noted in each case and those who were discharged were followed up to a minimum of 8 months and a maximum of 20 months.

\section{RESULTS}

All patients included in this study were operated on within 48 hours (Table 1). There were 15 males and 110 females. The median age was 80 years and the range 66-95. The female to male ratio was 7:3:1. A total of 26 patients died in hospital, 11 of them within one month of the operation. The median in-hospital time for the survivors was 31 days and the range 3-161 (Table 2). By the time the final review was made seven more

Table 1 Type of fracture and operation performed

\begin{tabular}{lc}
\hline Type of fracture & No. of patients \\
\hline Intracapsular & 59 \\
Trochanteric & 58 \\
Subtrochanteric & 2 \\
Trochanteric complicating & 4 \\
$\quad$ subtrochanteric & 2 \\
Unknown & 125 \\
Total & No. of patients \\
Type of operation & 81 \\
& 14 \\
Pugh's Nail Plate & 16 \\
Thompson's Arthroplasty & 5 \\
KY Nail & 7 \\
Enders (Condylocephalic) Nails & 2 \\
Total Hip Replacement & 125 \\
Jewett Nail Plate & \\
Total &
\end{tabular}

Table 2 Hospital time

\begin{tabular}{lrrrr}
\hline & No. & $\%$ & $\begin{array}{c}\text { Hospital stay } \\
\text { median (days) }\end{array}$ & Range \\
\hline Hospital Mortality Group & 26 & 20.8 & 43 & $6-300$ \\
Survivors & 97 & $77 \cdot 6$ & 31 & $3-161$ \\
Unknown discharge time & 2 & 1.6 & & \\
Total & 125 & $100 \cdot 0$ & & \\
\hline
\end{tabular}


patients had died after discharge, their survival time ranging from 80 days to 8 months post-operatively.

Using the Chi-square test with Yates' correction the factors identified at admission were compared with each other as prognostic indicators of mortality. The most significant of these was mental state $(p<0.0005)$, followed by associated illness $(0.005>p>0.001)$, then mobility $(0.05>p>0.025)$ and age $(p<0.034)$ (see Tables 3-5). (Age for the Mortality Group and Survivors was compared using a $t$-test fore

Table 3 Mental state on admission

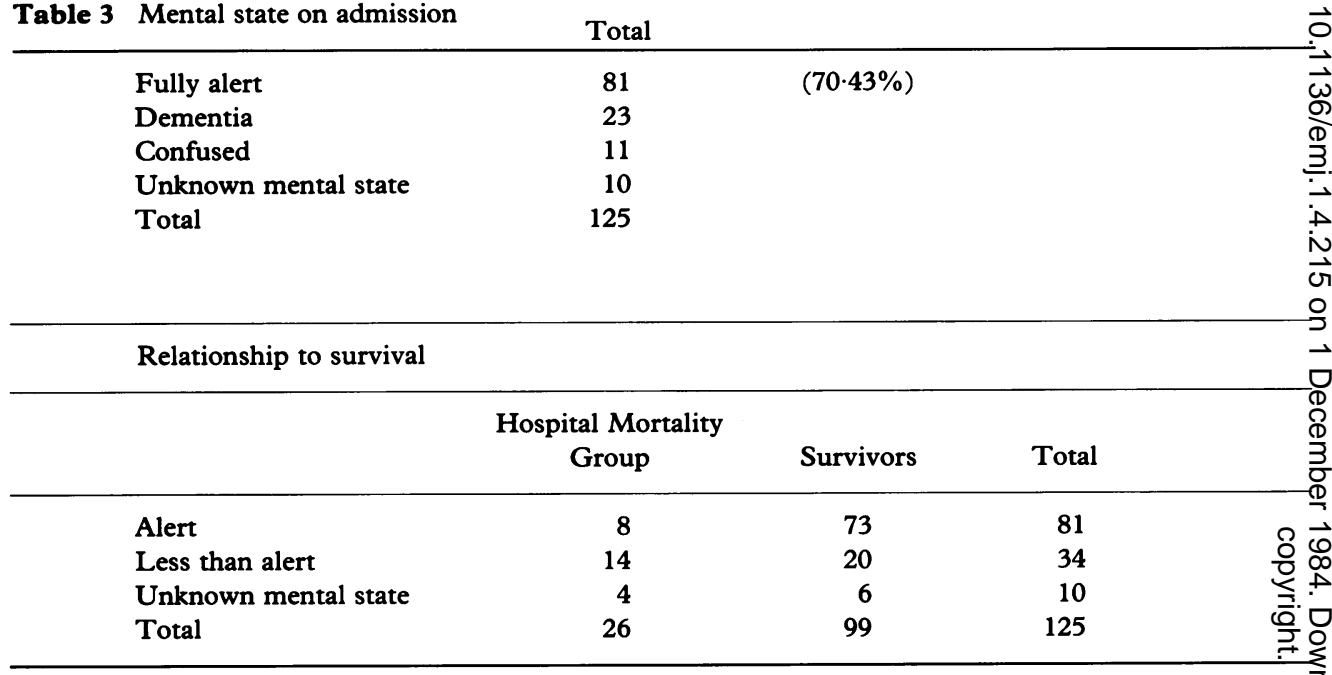

The difference in pre-fracture mental state between the Hospital Mortality Group and the Survivors was the् most significant factor $(p<0.0005)$.

independent groups.) There was no significant statistical difference between patients引응 who came from home and those who came from institutions. Patients not taking medication were compared with those on one or more drugs. The difference was not: statistically significant (see Tables 6 and 7). A total of 30 patients were on diuretics and $\frac{\mathrm{D}}{3}$ 79 patients were on medications which can produce dramatic orthostatic hypotension: and syncopal falls. A total of 49 patients were taking a medication which is known to produce bone weakness and predispose to fracture (Table 7). Medications taken byo patients in this study can promote falls or fracture; however, patients on medication were not generally ill or at a special risk.

Age (statistically just significant) is not a very helpful predictor of the outcome of this fracture.

Of those patients with post-operative general complications, $32.5 \%$ died eventually ${ }^{N}$ in hospital, compared with $2 \cdot 19 \%$ of those not having general complications. This is a very striking difference, and is the most significant of all the variables considered $\omega$ relating to survival, including the pre-fracture factors (see Table 8).

Of those patients with one or more local complications, $53 \%$ died in hospital compared with $16 \%$ of those not having local complications. The difference was statistically@ 
Table 4 Associated illness on admission

No. of Patients

Significant respiratory disease $\quad 16$

Gastrointestinal disease $\quad 15$

CVA (5), Epilepsy (4), TIA (3), Parkinsonism (2) 14

Cardiac incompetence on admission 10

History of MI or Angina $\quad 10$

Diabetes 9

Hypertension above $170 / 100 \quad 8$

Joint disease affecting mobility $\quad 8$

Severe eye/ear disability $(4+2) \quad 6$

Cancer 6

Total incontinence of urine 5

Total incontinence of faeces and urine 5

Renal failure $(B U>15 \mathrm{mml} / \mathrm{l})$

Urinary tract infection 2

Associated fractures 3

Anaemia 2

Varicose veins 1

Thyroid disease 1

Falls cause unknown 1

Previous lower limb amputation 1

There were 13 patients with previous upper femoral fracture and four patients with previous major joint replacements; four patients had fractures prior to admission, with no residual functional disability. These conditions were therefore excluded.

Relationship to survival

$\begin{array}{lccc} & \text { Hospital Mortality } & & \\ \text { No illness } & \text { Group } & \text { Survivors } & \text { Total } \\ \text { One or more } & 3 & 50 & 53 \\ \text { Total } & 23 & 49 & 72 \\ & 26 & 99 & 125\end{array}$

There is more associated illness in the Hospital Mortality Group.

This is statistically significant $(0.005>p>0.001)$.

Table 5 Mobility prior to admission

\begin{tabular}{lccr}
\hline & $\begin{array}{c}\text { Hospital Mortality } \\
\text { Group }\end{array}$ & Survivors & Total \\
\hline Full & 11 & 63 & 74 \\
1 stick & 5 & 11 & 16 \\
2 sticks & 0 & 2 & 2 \\
Frame & 6 & 8 & 14 \\
Wheelchair & 1 & 0 & 1 \\
Not known & 3 & 15 & 18 \\
Total & 26 & 99 & 125 \\
\hline
\end{tabular}


Relationship to survival

\begin{tabular}{|c|c|c|c|}
\hline & $\begin{array}{l}\text { Hospital Mortality } \\
\text { Group }\end{array}$ & Survivors & Total \\
\hline Full & 11 & 63 & 74 \\
\hline With aid & 12 & 21 & 33 \\
\hline Not known & 3 & 15 & 18 \\
\hline Total & 26 & 99 & 125 \\
\hline
\end{tabular}

The survivors had better pre-injury mobility than the mortality group $(0.05>p>0.025)$.

Table 6 Source of admission

\begin{tabular}{|c|c|c|c|}
\hline Patient's origin & $\begin{array}{c}\text { Hospital } \\
\text { Mortality } \\
\text { Total }\end{array}$ & Group & Discharged \\
\hline Home & 94 & 17 & 74 \\
\hline Elderly persons' home & 6 & 3 & 1 \\
\hline Nursing home & 6 & 4 & 2 \\
\hline Mental hospital & 14 & 1 & 14 \\
\hline Other hospital & 5 & 1 & 6 \\
\hline Not known & & & 2 \\
\hline Total & 125 & 26 & 99 \\
\hline
\end{tabular}

Table 7 Regular medication prior to admission

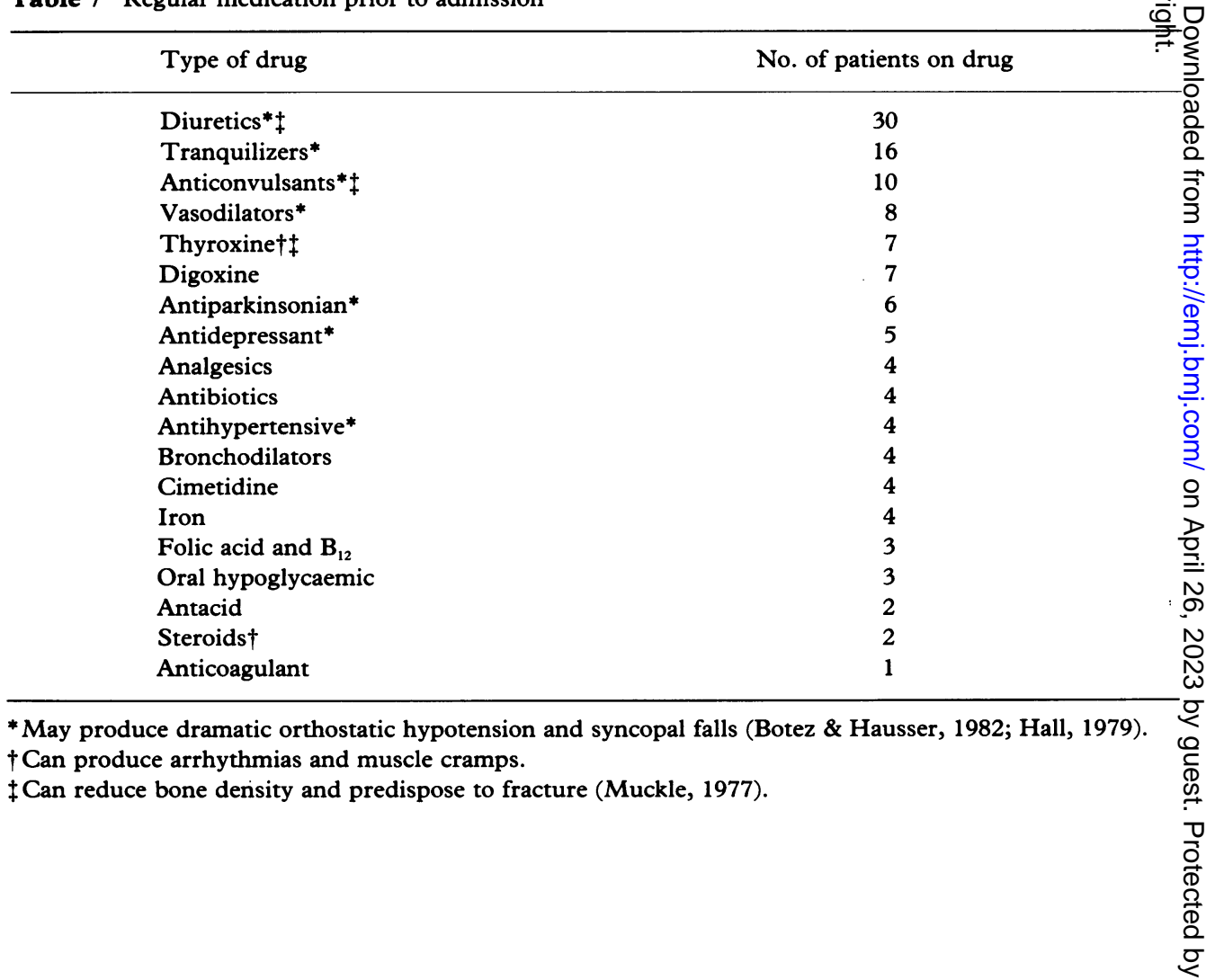


Table 8 Post-operative general complications

No. of patients

Post-operative anaemia requi
Urinary tract infection $\dagger$
Total confusion
Pneumonia (6 pulmonary em
Episodes of confusion
Bed sores
Renal failure (BU > 15)
Cardiac failure and MI
Incontinence
Gastrointestinal disease
Retention of urine
Cerebrovascular accident
Ketosis in a diabetic
Other surgery:
Carcinoma colon
Perforated duodenal ulcer
Prostatectomy
Diverticular peritonitis

Ketosis in a diabetic

Carcinoma colon

Perforated duodenal ulcer

Diverticular peritonitis

* Clinical and $\mathrm{x}$-ray diagnosis

$\dagger$ Needed treatment

Relationship to survival

Hospital Mortality

Group Survivors Total

$\begin{array}{lrrr}\text { Patients with no } & & & \\ \quad \text { complications } & 1 & 47 & 48 \\ \text { Patients with one or more } & 25 & 52 & 77 \\ \text { Total } & 26 & 99 & 125\end{array}$

Post-operative general complications in the Hospital Mortality Group were the most significant factor $(p=0.0002)$.

significant but less important than the general complications or pre-fracture mental state (see Table 9).

The actual cause of death, where available, is given in Table 10.

\section{Length of hospitalization}

The data were analysed using a stepwise linear regression programme. The variable that is the best predictor of length of stay is post-operative general complications, which is significant $-\mathrm{p}<0.001, t=3.4$ with 96 degrees of freedom. 
Table 9 Post-operative local complications

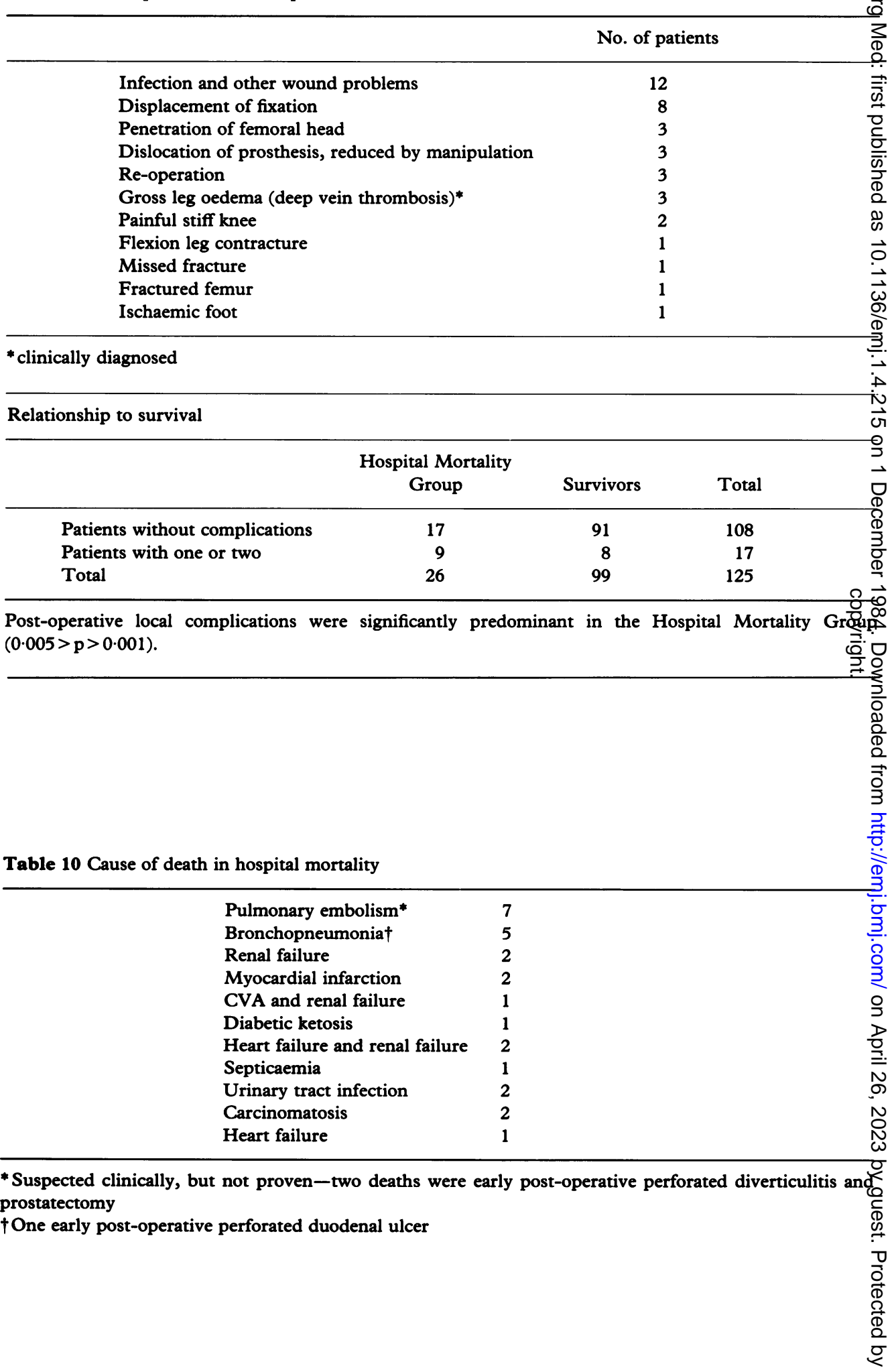


Having included this variable, none of the other variables, when included, are statistically significant at the 0.05 probability level. Length of stay is a positively skewed variable. When the log of the length of stay was used, post-operative general complications is still the best variable for predicting length of hospitalization$\mathrm{p}=0.001, t=3.30$ with 96 degrees of freedom. Considering only those variables that were known before the fracture, then mobility is significant $-p=0.046, t=2.03$ with 96 degrees of freedom. No other variable (including age) when added is significant at the 0.05 probability level.

\section{DISCUSSION}

It appears that an accurate assessment of mental state in the accident and emergency department at the time of admission can predict survival after operation for a fracture of the hip. The elderly may be confused by the accident, or by pain, and disoriented due to the sudden change in their environment. In these cases enquiries from relatives, care assistants, etc. will reveal the true pre-fracture mental state. Why is the mental state so important with respect to mortality? Is it due to lack of motivation for mobility or poor nutritional state from inadequate communication? This is at present being investigated in a large prospective study.

Medication plays an important part in the treatment of the elderly. Studies have indicated that there is a relationship between medication and the patient's tendency to fall (Duthie, 1981; Sobel \& McCart, 1983) and between medication and the incidence of fracture (Muckle, 1977; Muckle \& Miscony, 1979). Uncertainties have been expressed by Sobel \& McCart (1983) as to whether the medication is a causal factor in the fall, or simply an indicator of poor health which would predispose to falls. In our study, although more patients among those who died were on medication as compared to survivors, this did not reach statistical significance, indicating that being on medication is of no prognostic importance. It is true that drugs brought in with the patient may point to a particular illness, but these may, on the other hand, be misleading. It is not uncommon for the elderly person, who has been put on a drug for a specific illness, to continue it for prolonged periods afterwards, when it is not needed, and this is not always the patient's fault.

In this study, the source of admission was found to be an unreliable criterion for assessment. This is not the same finding as that of Miller (1978) and Evans et al. (1979), who stated that patients from institutions are at special risk. This may be because the criteria for institutionalization differ not only from country to country, but between areas of the same nation, and with individual family structures.

In this study, pre-fracture mobility was found to be a useful early predictor of the likely length of hospitalization.

Post-operative general complications were a more significant indicator of unsuccessful outcome to operation than failure of operative technique. It is suggested that most general complications after operation are preventable, viz. post-operative confusion, urinary tract infection, pneumonia, deep venous thrombosis and pulmonary embolism, bed sores and renal failure. As for most operations, post-operative 
complications are the major contributor to mortality and it is therefore important tha measures are taken to avoid them if patients have already been shown to be at risk in the accident and emergency department. Not surprisingly, regardless of factors alread\%. present on admission, the length of stay in hospital was more likely to be affected b post-operative complications. It is recommended that medical staff in the accident ang emergency department determine accurately the mental state and mobility of patients before their fracture. When these factors are unfavourable it is important that every ste is taken to avoid post-operative complications.

\section{ACKNOWLEDGEMENT}

We wish to thank the Consultant Orthopaedic Surgeons at the Victoria Infirmary Glasgow for permission to study their patients.

\section{REFERENCES}

Baker R. B., Duckworth T. \& Wilkes E. (1978) Mental state and other prognostic factors in femoral fracture of the elderly. Fournal of the Royal College of General Practitioners 28, 557-559.

Botez M. I. \& Hausser C. O. (1982) Falls. British fournal of Hospital Medicine 494-503.

Ceder L., Elmquvist D. \& Svensson S.-E. (1981) Cardiovascular and neurological function in elderly patien sustaining fracture of the neck of the femur. Fournal of Bone Foint Surgery 63, 560-566.

Dahl E. (1980) Mortality and life expectancy after hip fractures. Acta Orthopaedica Scandinavica 51, 163-

Duthie R. B. (1981) Orthopaedic services: waiting time for out-patient appointments and in-patient treatment. Report of a Working Party to the Secretary of State for Social Services, p. 30.

Evans J. G., Prudham D. \& Wandless I. (1979) A prospective study of fractured proximal femur: factore predisposing to survival. Age and Ageing 8, 246.

Hall M. R. P. (1979) Diseases of Old Age. p. 36. London, Update Publications.

Jensen J. S. (1984) Determining factors for the mortality following hip fractures. Injury 15, 411-414.

Jensen J. S. \& Tondevold E. (1979) Mortality after hip fractures. Acta Orthopaedica Scandinavica 50, 161-167.

Miller C. W. (1978) Survival and ambulation following hip fracture. fournal of Bone foint Surgery 61A 930-933.

Muckle D. S. (1977) Iatrogenic factors in femoral neck fractures. Injury 8, 98-101.

Muckle D. S. \& Miscony Z. (1979) Fractures of the femoral neck in the 'young' elderly. Injury 12, 41-44

Sobel K. C. \& McCart G. M. (1983) Drug use and accidental falls in an intermediate care facility. Drug Intelligence and Clinical Pharmacy 17, 539-542.

Received 5 April 1984; editorial comments to authors 4 fune 1984; accepted for publication 9 fuly 1984 